\title{
Factors Influencing the Use of ICT in Greek Primary Education
}

\author{
Vasileios Neofotistos ${ }^{1} \&$ Vasiliki Karavakou \\ University of Macedonia, Thessaloniki \\ School of Social Sciences, Humanities and Arts \\ Department of Educational and Social Policy
}

Received 28 September 2018 - Revised 25 November 2018 • Accepted 30 November 2018

\begin{abstract}
Despite the efforts made to upgrade hardware and software, in primary education in the Greek educational system, the use of ICT in classes is particularly low-level. In this study, we analyze the role of accessibility to ICT school infrastructure and the teachers' characteristics concerning their skills and attitudes in order to explain the use of ICT in education. We use data from teachers in Greek primary education. The sample consists of 284 teachers (92 male and 192 female) who teach in various elementary schools across the Greek region. Analysis was performed using Oneway ANOVA and Pearson correlations. The main results show that the availability of digital media, school hardware and Internet connection infrastructure, teacher training in ICT and their pedagogical background seriously influence the use of ICT in the classroom. In particular, media accessibility is seen as the dominant factor for ICT implementation in Primary Education. Based on the findings, recommendations are made in order to guide Greek education policy administrators to encourage the use of ICT in classrooms.
\end{abstract}

Keywords: ICT, primary education, constructivism, attitudes.

\section{Introduction}

The integration of ICT into a country's education system is a multi-component project that involves logistics, human resources, curricula and the necessary training actions. It also depends on the economic resources available for the project, the general educational policy and the social conditions that prevail at that time. In Europe, ICT integration was based on the i2010 strategic framework (European Commission, 2005), which considers it necessary that all EU citizens develop digital skills. The European Commission is now focusing on the development of research, creativity and innovation, and the introduction of ICT as a holistic tool at all levels of education (European Commission, 2009). The transformation of the modern era into a time based almost solely on digital technology has influenced education. From practical and procedural knowledge, emphasis is now placed on the development of conceptual knowledge and, above all, of metacognition, evolving the educational systems themselves (Anderson, 2008), altering the concept of literacy itself. As a result of this development, the teachers themselves need to develop

${ }^{1} \mathrm{PhD}$ candidate.

(C) Authors. Terms and conditions of Creative Commons Attribution 4.0 International (CC BY 4.0) apply. Correspondence: Vasileios Neofotistos, University of Macedonia, 156 Egnatia Street, GR-546 36

Thessaloniki, Office KZ2, 205, GREECE. E-mail: vneof@uom.edu.gr. 
their skills to apply a variety of teaching methods during the educational process with the help and use of ICTs. Furthermore, many educational systems have sought to increase the availability of computers and internet connections in classrooms. This equipment is an efficient tool for study, a valuable source of information, and a flexible support for teaching (Tondeur, van Braak \& Valcke, 2007).

- Teacher pedagogical background seriously influences the use of ICT in the classroom.

- Media accessibility is seen as the dominant factor for ICT implementation in Primary Education.

- Continuous teacher training in ICT is a general requirement.

According to Romeo, Lloyd and Downes (2012), the process of integration and approach of ICT by the candidate teachers is distinguished in four phases: (a) the exploratory phase, in which teachers express the intention to implement ICT; (b) the implementation phase, in which there is an initial use of ICT to a limited extent, (c) the integration phase, in which ICT is fully implemented, and (d) the expansion and leadership phase in which teachers use ICT as a holistic tool in the school culture.

The provision of equipment and infrastructure is the prerequisite for the implementation of any ICT policy designed in a national context. In recent years, specific programs have been developed for the provision on ICT infrastructures in schools in some countries. According to the Vacchieri report (in Gil-Flores, Rodríguez-Santero \& Torres-Gordillo, 2017), the common adoption of ICT in the education system has not influenced Europe's policymakers to implement different strategies. Hungary, the Czech Republic, Portugal, Germany, Estonia and the Italy finance the schools that meet certain conditions. Other countries, such as Spain and United Kingdom, try to equip all schools. In France, Italy, Malta, Poland, Portugal, the Ministry of Education cooperates with private companies, providing incentives for students or families to acquire a netbook and in some cases broadband connection. In Greece, during the programming period of the Second Community Support Framework (1994-1999), the introduction of New Technologies in education was the first to be implemented. Subsidies from the Operational Programme for Education and Initial Vocational Training were then absorbed. Today, in times of economic recession, most schools are trying to renew their equipment either using their own economic resources or with the help of institutions and private companies. The Greek economy and, consequently, the educational system has been afflicted during the last ten years by one of the deepest recessions. As an unfortunate result, the country has witnessed major inequalities and signs of educational and social exclusion. Agreements to rescue the Greek economy required drastic cuts in spending, which resulted in turn to the downgrading of the quality of education offered by the public system (Pickles, 2015). The subsequent economic crisis is a factor that explains (at least partially) the enormous deficiencies and the bad state in general in the infrastructure regarding ICT. The merging of schools and departments in Primary and Secondary Education, the reduction of infrastructure funds and, above all, the reduction of teachers' remuneration are affecting their attitudes. Economic and occupational uncertainty enhances their work-related anxiety and professional exhaustion, interrupting the smooth functioning of the educational process. According to Aristotle, the roots of education are bitter, but the fruit is sweet. In this spirit, education may be seen as an expensive and time-consuming investment but its final result is stability and growth. The application of this interpretation of Aristotle's thought in the current economic crisis in Greece is important: if the government continues to degrade one of the most essential areas of education, when the financial crisis subsides, the economy will not maintain its stability (Ortiz, 2013).

Regarding the integration of ICT into the curriculum, most countries set out general guidelines for ICT. These guidelines relate to different regions, communities and, in some cases, even schools, such as the example of Ireland. In Greece, Cyprus and Turkey, the curriculum is entirely determined by the Ministry of Education. Focusing on the Greek context where this study 
was conducted, initial approaches to the introduction of new technologies in education followed the techno-centric approach. "Informatics" was considered an autonomous subject, which could be integrated into the curriculum and taught only in Secondary Education. The primary objective was to acquire knowledge and skills on computer operation and on algorithmic programming thinking. The curriculum for computer science as a cognitive school subject aimed at preparing students as professionals in the field to meet the growing needs of the blooming software industry at the time. Pedagogically, a vertical approach was followed (based on the learning theory of behaviorism), which defines learning as a visible change in behavior that results from experiences and exercises posed by the teacher (Good \& Brophy, 1990). The introduction of "Informatics" began in the period 1983-1985 from the vocational secondary school (Technical-Professional Lyceum). It was followed by the introduction of the subject in junior high school (Gymnasium) and finally established in the General Lyceum in 1998. "Informatics" was also gradually introduced in Primary Education. It was piloted in the 1996-1997 school year. In 2002-2003, the subject of "Informatics" is introduced into the institution of the whole-day school. In the next school year, 2003-2004, the subject is renamed to "New Technologies in Education". The Unified Reformed Educational Program was piloted in 2010-2011, marking upgrades in Computer Science courses, paving the way for the full development of the Digital School and the new pilot curricula. In 2010, after the updating of the curriculum, the course is introduced in the afternoon teaching zone of schools as "Information and Communication Technologies" (ICT). Since 2016 the lesson has been introduced into all elementary schools of the country.

In a wider context the Ministry of Education, Research and Religious Affairs has recently established the General Directorate of Primary and Secondary Education of the Department of Support for New Technologies and Innovation. The responsibility of the Associated Section concerns the support of digital educational policy and the creation of working groups for conducting surveys and studies in cooperation with the supervised bodies of the Ministry. It will also investigate and record the impact and utilization of digital technology and innovation education programs related to teacher training, the use of educational digital content and digital media upgrade equipment in the educational community (Ministry of Education, Research and Religious Affairs, 2016). In general, developed countries consider ICT integration in education as a key strategy for enhancing citizens' quality of life, innovation and national economic competitiveness. The US government updates the National Technological Education Plan about almost 5 years, stating clearly that its technology-driven structural reforms will be implemented in the education system. In the United Kingdom, JISC a membership organization providing digital solutions for UK education and research promoted ICT in educational strategy and defined its area of implementation in the United Kingdom. Since 1996, Singapore has been developing ICT development projects in education every five years, providing strategic teaching on ICT in education (Wu et al., 2016).

Current evidence suggests that, although the use of technology during the teaching and learning process is steadily increasing (Berrett, Murphy \& Sullivan, 2012), achieving technological integration is still a complex process of educational change. This is due to the fact that the use of technology in schools is still extremely varied and, in many cases, limited (Spector 2010). Achieving the goal of a holistic approach of teaching and learning, through technology, is not solely dependent on technology-related factors (Kimmon et al., 2015). Teacher's personal pedagogical beliefs play also a key role in their pedagogical decisions about whether and how to integrate technology into their classroom practices (Deng et al., 2014). The combination of ICT and learning theories in the light of curriculum proposals is the key to a structured educational policy with successful results. However, the introduction of such a program has caused a variety of reactions, due, mainly, to poor information, training and logistical infrastructure. According to Dede (2008), the contribution of ICT to the acquisition of knowledge and skills from students, in relation to the curriculum of each course, depends on the tools, applications, digital media and virtual environments used in the educational process. This approach has delineated new rules and 
significantly different educational attitudes. In recent years, the leadership of the Ministry of Education believes that information technology and ICT are both "structural" elements for future citizenship. Application of any template in schools is intended to make computing not a distinct subject but an important tool, motivating learners to use it throughout the lifelong learning process. Similarly, Pelgrum and Voogt (2009), cite the need for the development of a collaborative culture that promotes the introduction of ICT into the teaching and learning process.

\section{Factors associated with ICT use}

Several researchers have investigated factors that have a significant impact on the use of ICT in classroom instruction (Flanagan, \& Jacobsen, 2003; Lim, 2006; Vanderlinde, \& van Braak, 2010; Yuen, Law \& Wong, 2003). Based on the literature, the factors that influence the holistic integration of ICT in the curriculum focus mainly on the characteristics of teachers, including gender (Tezci, 2011), teachers' attitudes towards ICT (Drent \& Meelissen, 2008), teachers' pedagogical beliefs (Tondeur et al., 2016) and ICT training (Tondeur et al., 2008). However, other researchers have highlighted factors that influence the use of ICT and come from the wider environment of a school community (Flanagan \& Jacobsen, 2003; Yuen, Law \& Wong, 2003). They mention the school culture (Tezci, 2011), ICT educational policy (Tondeur et al., 2008; Vanderlinde, van Braak \& Dexter 2012), ICT infrastructure (Tondeur et al., 2008) and institutional and technological factors (Buabeng-Andoh, 2012).

The implementation of ICT in the educational process depends mainly on the teachers' own skills to exploit hardware and software as much as possible. The term "ICT skills" refers mainly to the concept of digital literacy which involves the use of basic ICT tools. Anderson (2008) refers to the concept of applied information literacy including both the areas of technical skills and knowledge areas. These areas are part of a teacher's ability to effectively implement ICT in the learning process by designing and organizing ICT-based themes and assessing learning outcomes. The issue is the combination of pedagogical and technological knowledge of ICT content, which is determined by the Technological Pedagogical Content Knowledge (TPACK) model of Mishra and Kohler (2006).

The development of teachers' ICT skills internationally, and specifically according to the American system, is based on the following six key areas of the range of competencies (Thomas \& Knezek, 2008):

- Possession of knowledge and skills related to the handling of technologies.

- Design of learning experiences and environments using ICT.

- Implementing policies and methods for integrating ICT into curricula to improve learning outcomes.

- Use of ICT as an evaluation tool.

- Use of ICT by teachers to increase their productivity and practices.

Regarding the teachers' attitudes towards computer use and, more generally, towards ICT, these depend largely on factors relating to self-efficacy or confidence (Al-Khaldi \& Al-Jabri, 1998; Beckers \& Schmidt, 2003), computer anxiety (Al-Khaldi \& Al-Jabri, 1998; Beckers \& Schmidt, 2001), computer liking (Al-Khaldi \& Al-Jabri, 1998), perceived usefulness (Davis, 1993), perceived ease-of-use (Davis, 1993), the level of computer skills (Beckers \& Schmidt, 2001), and how one perceives the effects of use computing in society (perceived consequences for society) (Beckers \& Schmidt, 2003). Lee and Lee (2014) support the importance of encouraging teachers' self-employment beliefs as regards technological integration, teacher attitudes towards computers, computer use, and the design and development skills of a lesson using digital media.

Effective integration of ICT into all aspects of school life requires reliable hardware and software infrastructure as well as broadband internet connections. On the other hand, 
negative influence may be caused by the absence or aging of technological equipment, lack (or malfunctioning) of the Internet, inaccessibility to IT laboratories, and various limitations resulting from the curriculum of each subject (Legontis, 2015; Lockwood \& Cornell, 2013). In this research we used the theoretical model Will, Skill, Tool (WST) designed solely to assess the level of integration of ICT in the learning process (Knezek, Christensen \& Fluke, 2003). According to the model, the variables that influence the integration of ICT in the learning process are: (a) teacher attitudes towards ICT; (b) their skills in handling and using applications; and (c) access to ICT tools (Knezek \& Christensen, 2003).

\section{Research framework and research questions}

This study analyzes variables associated with the frequency of ICT use in course activities in Primary schools. Moreover, according to Bingimlas (2009), the lack of digital technology infrastructure is an inhibiting factor for the integration of ICT into the educational process. From the teachers' perspective data showed that equipment is still the biggest obstacle to the use of ICT, followed by pedagogical factors" (European Commission, 2013). However, the lack of access to resources is not, in itself, the main reason for the reduced use of ICT in primary education. Assessment of a general form or the feeling of a person's preference or disposition towards computers and activities that use them are the structural elements that define computer attitude (Smith, Caputi \& Rawstorne, 2000). According to Palaegeorgiou (2006), in relation to the Theory of Reasoned Action (TRA) concerning the use of computers, the users' attitude towards computers has an impact on future moods that generally affect the real use of computers. The adoption model (Hall \& Hord, 2015) argues that each person responds to a new program, or innovation, according to his stance and beliefs, regardless from a large extent of the supply of materials or resources. The integration of technology into education is particularly dependent on the acceptance of computers by teachers (Kumar, Rose \& D' Silva, 2008). Based on TRA theory, the Technology Acceptance Model (TAM) proposed by Davies (1989) is one of the most commonly used and validated models of technology adoption (Teo, Ursavas \& Bahcekapili, 2012). TAM explains how users accept and use technology by focusing on two dimensions: perceived utility (PU) and perceived ease of use (PE). PU is defined as a person's belief in a particular technology that affects the performance of his work, while PE is defined only as a person's belief in a particular technology.

Hargreaves (1994), points out that the quality, breadth and flexibility of a teacher's work is directly related not only to his professional development but also to the personality he has developed. According to Stiegelbauner (1992), beyond the knowledge and skills, it is vital that the teacher maintains the "desire to have a positive effect on the life of his pupils". Teaching is a moral practice that does not exclude its technical dimension but places it in a wider context of values (Elliott, 1991). A successful teaching process presupposes the teacher's emotional intelligence and exudes "pleasure, passion, creativity, challenge and joy" (Hargreaves, 1995). It presupposes not only the ability but the desire for success. In this context, the attitude of the teacher becomes a critical factor for the final outcome of any innovation (Prawat, 1996), since his beliefs influence practice, but at the same time the practice itself and the subsequent experience influences the formation of beliefs. Mavroyorgos (1999), advocates the above, stating that teachers' consensus is the prerequisite for the introduction of any innovations or reforms in the educational process. Therefore, for developmental educational strategies to be successful they need to influence attitudes and to lift teachers' resistance to change first (Day, 1999). Teachers in Greece, according to Plomaritis, Maletskos and Fousteris (2015), show positive attitudes in the introduction of innovations in education. They perceive innovation primarily as "educational change", "creativity development" and "improving the quality of the educational project" and secondarily as "culture of novelties". 
The purpose of this study is to explore the factors that influence the use of ICT in the educational process in relation to the technological infrastructure of schools, accessibility, attitudes of teachers and their pedagogical perceptions.

Specifically, our research questions are as follows:

(a) Is there a relationship between the digital infrastructure of a Primary Education school in Greece that involves access to hardware, software, Internet and teacher ICT use during the educational process?

(b) Is there a relationship between the attitudes and beliefs of teachers towards computers and the use of ICT in the educational process?

(c) Is there a relationship between teachers' pedagogical perceptions and the use of ICT in the educational process?

(d) Is there an impact of teachers' age on infrastructure accessibility?

(e) Is there an impact of teachers' years of service in education on accessibility?

In addition, variables related to demographic characteristics such as gender, specialization and pedagogical training of teachers were examined in relation to their degree of influence on the use of ICT in the classroom.

\section{Method}

This study is an analysis that uses data obtained from primary schools across the Greek territory. It aims to obtain indicators and analysis regarding teachers' beliefs and practices which can provide a basis for the review and development of policies that promote improvements in teaching and learning in Greece.

\section{Participants}

The random sampling method was used for the selection of teachers from the 13 educational areas of the country. In each educational area, different schools were selected according to the size of each layer. From these schools we use data from 284 teachers (92 male and 192 female).

\section{Instrument}

In the context of quantitative empirical research, the descriptive sampling method was selected using a questionnaire (Cohen \& Manion, 1994). The wide five-dimensional Likert measurement scale was used to minimize the effects that may result from incorrect answers due to misunderstanding the meaning of the content of a variable, or the wrong choice in one of the variables. The Cronbach's Alpha internal coefficient was calculated for the reliability of the questions. Factor analysis, and more specifically the Principal Component Analysis, was used for parts of the questionnaire that mainly concerned views and attitudes of the participating teachers.

The questionnaire developed for the purpose of this research consisted of questions that were divided into 5 categories: (a) demographic data; (b) pedagogical perceptions; (c) computer attitudes; (d) accessibility to ICT infrastructure; and (e) use of ICT in the educational procedure. This questionnaire was posted on a digital platform and sent via the e-mail of the researcher to the emails of the selected primary school units, with the request to promote messages to the personal electronic accounts of the service teachers in those schools. In particular, the first 
part of the questionnaire consists of 8 questions and concerns demographic factors such as gender, age, specialty, type of school, area (urban, semiotic, rural, island), educational experience, training in ICT and pedagogy.

The second part of the questionnaire used 15 questions of the questionnaire "The Emerging Theory / Philosophy of Teaching and Learning" (Sass, 2003). These questions were used in order to highlight the pedagogical perceptions of teachers and were tailored to the Greek educational system. The questions concern the following points:

- $\quad$ Students need praise, good grades, or other rewards in order to learn effectively (B1).

- $\quad$ Learning occurs when there is a measurable change in student behavior (B2).

- $\quad$ For the most effective learning, students' errors should be minimized and successes maximized (B3).

- Students learn best when they have the opportunity to observe a demonstration or example of what is being taught (B4).

- $\quad$ Learning is growing through the accumulation of information (B5).

- The teacher should be a facilitator of learning rather than a presenter of knowledge (S_C1).

- Students can be trusted to find their own goals and should be given choices as to what and how they will learn (S_C2).

- Learning increases through interaction with others (S_C3).

- Collaborative learning is an effective way to enhance student learning (S_C4).

- Teaching offers meta-cognitive skills (S_C5).

- The best learning occurs when students discover answers for questions and problems themselves rather than having the answers told to them (R_C1).

- It is important to help students organize their thinking by teaching them general concepts (or schemes) before they learn more specific information (R_C2).

- Meaningful learning occurs, when students mentally create knowledge structures (schemes or concepts) by combining new ideas with their prior knowledge (existing schemes or concepts) (R_C3).

- Teachers must be active knowledge mediators (R_C4).

- Learning involves conscious decision-making (R_C5).

The part of the questionnaire on teacher attitudes towards ICT, accessibility to ICT infrastructure and the frequency of use of ICT to support teaching and learning was based on the corresponding questionnaire "ICT in School Inventory 2013: Subsequent Questionnaire" (Cosgrove, Butler, Leahy, Shiel, Kavanagh, \& Creaven, 2013) adapted to the needs of this research and the design of the Greek educational system. This part included 22 questions:

- I have access to a computer in classroom (Ac1).

- I have access to a digital projector (Ac2).

- I have access to an interactive whiteboard (IWB), (Ac3).

- I have access to Internet (Ac4).

- I have access to educational software (Ac5).

- I have access to the computer lab (Ac6).

- It increases the academic performance of students (At1).

- It promotes student collaboration (At2).

- It promotes the development of communication skills (e.g., writing and presentation), (At3).

- It encourages students to participate more in learning activities (At4).

- It improves the atmosphere in the classroom (At5).

- Use presentations for lesson items (U_IT1).

- Use computer based simulations and virtual labs (U_IT2). 
- Use applications such as word processing and presentation software to prepare resources for class (U_IT3).

- Create multimedia resources, incorporating sound, video, images or other digital media for use in class (U_IT4).

- $\quad$ Record student work for assessment purposes (e.g., digital camera, digital video), (U_IT5).

- Support assessment of learning (formative and summative assessment), (U_IT6).

- Use curriculum relevant online resources for lesson preparation (e.g., websites, blogs and wikis), (U_Int1).

- Support collaboration between students for learning (e.g., live chat, online forums, school VLE), (U_Int2).

- Publish students' work online (U_Int3).

- Use social networks in teaching and learning (U_Int4).

- Communicate with students (e.g., email), (U_Int5).

- Use web questions (U_Int6).

\section{Factors}

This study analyzes variables related to the factors that affect the frequency of use of ICT by primary school teachers during their courses. The first group of variables provides information regarding ICT infrastructure in schools: computers for instruction, internet access and software for instruction. The second set of variables relates to teachers' beliefs about learning theories and classroom use. The third set of variables corresponds to teacher's attributes related to beliefs, behaviors and educational performance. The variables were allocated into seven factors based on the prediction of the main component factor analysis. The factors are presented below:

- The factor "ICT accessibility" is based on six variables (Ac1...Ac6).

- The factor "behaviorism" is based on five variables (B1...B6).

- The factor "radical constructivism" is based on five variables (R_C1...R_C5).

- The factor "social constructivism" is based on five variables (S_C1...S_C2).

- The factor "attitudes towards ICT" is based on five variables (At1...At5).

- The factor "frequency of IT use" to support teaching and learning is based on six variables (U_IT1...U_IT6).

- The factor "frequency of internet" use to support teaching and learning is based on six variables (U_Int1...U_Int6).

The factors correlation synthesizes the structure of this research. The importance of ICT training according to the views of educators was also examined, using the variable (Tr1).

\section{Data analysis}

Principal component analysis (PCA) with varimax rotation was conducted to statistically determine the number of factors that should be retained in the questionnaire. The PCA helps to identify the number of factors to be interpreted by extracting the maximum variance from the dataset to each item (Tabachnick \& Fidel, 2007). It quantifies the importance of each, describing the variability of a set of data. It also compresses data, reducing the number of factors without much loss. Prior to the implementation of the PCA, the suitability of data for factor analysis was evaluated. The Bartlett's test of sphericity and Kaiser-Meyer-Olkin's sampling rate measurement $(\mathrm{KMO})$ were calculated. The significance $(\mathrm{p}<.05)$ of the Bartlett's test of sphericity and the values above .70 for the KMO index were considered appropriate. The reliability analysis was carried out by calculating alpha Cronbach for each measure. The credibility of a measure indicates the stability and consistency of the instrument to measure a concept and contributes to 
assessing the credibility of a measure (Sekaran \& Bougie, 2010). Alpha coefficients above .70 are considered acceptable (George \& Mallery, 2003).

\section{Results}

Table 1 presents the indexes of Descriptive statistics and the suitability evaluation. The Cronbach's alpha for each factor is considered acceptable with values above .75. The KMO statistical control has values above .75 proving the suitability of the sample.

Table 1. Internal Consistency, Means, and Standard Deviations for each factor of the questionnaire

\begin{tabular}{lccc}
\hline \multicolumn{1}{c}{ Factors } & $\mathrm{N}$ & Cronbach's a & Mean \pm SD \\
\hline Behaviorism (B) & 284 & .77 & $2.78 \pm .53$ \\
Radical Constructivism (RC) & 284 & .77 & $4.11 \pm .41$ \\
Social Constructivism (SC) & 284 & .81 & $4.12 \pm .43$ \\
Attitudes (At) & 284 & .76 & $3.81 \pm .56$ \\
Access (Ac) & 284 & .80 & $3.26 \pm .90$ \\
Use of Internet (U_Int) & 284 & .82 & $2.51 \pm .89$ \\
Use of IT (U_IT) & 284 & .83 & $3.04 \pm .87$ \\
\hline
\end{tabular}

Table 2 presents the relationships among factors. The relationship among the factors (Radical Constructivism, Social Constructivism, Attitudes, Access, Use of Internet and Use of IT) was examined using Pearson product-moment correlation coefficient. There was a strong, positive correlation between the variable Access and the variables Use of Internet $(r=.51, n=284, p<.01)$ and Use of ICT $(\mathrm{r}=.62, \mathrm{n}=284, \mathrm{p}<.01)$. Moreover, there was a strong positive correlation between the variables Use of IT and Use of Internet $(\mathrm{r}=.75, \mathrm{n}=284, \mathrm{p}<.01)$. Finally, there was a medium positive correlation between the variables Radical Constructivism and Social Constructivism $(\mathrm{r}=.472, \mathrm{n}=284, \mathrm{p}<.01)$.

Other correlations between the variable Attitudes and those of Access, Use of Internet and Use of ICT were significant at the .01 level but not strong. Pearson Correlation Coefficients among the Questionnaire's factors are shown in Table 2.

Table 2. Pearson Product-moment Correlations among questionnaire factors

\begin{tabular}{|c|c|c|c|c|c|c|c|}
\hline \multicolumn{8}{|c|}{ Correlations } \\
\hline & B & R_C & S_C & At & Ac & Use_Int & Use_IT \\
\hline \multicolumn{8}{|l|}{ Behaviorism (B) } \\
\hline Radical Constructivism (RC) & - & - & $.472^{* * *}$ & $.161^{* * *}$ & $.172^{* * *}$ & $.198^{* *}$ & $.190^{* *}$ \\
\hline Social Constructivism (SC) & - & - & - & $.171^{* *}$ & - & $.207^{* *}$ & $.185^{* *}$ \\
\hline Attitudes (At) & - & - & - & - & $.210^{* *}$ & $.264^{* *}$ & $.292^{* *}$ \\
\hline Access (Ac) & - & - & - & - & - & $.506^{* *}$ & $.623^{* *}$ \\
\hline Use of Internet (U_Int) & - & - & - & - & - & - & $.749^{* * *}$ \\
\hline Use of IT (U_IT) & - & - & - & - & - & - & - \\
\hline
\end{tabular}

A one-way analysis of variance between groups was conducted to explore the impact of age on accessibility. Participants were divided into four groups according to their age (group 1: 
23-30, group 2: 31-40, group 3: 41-50, group 4: >50). There was a statistically significant difference at the accessibility scores for the four groups: $\mathrm{F}(3,280)=4.53, \mathrm{p}=.004$. Despite reaching statistical significance, the actual difference in mean scores between the groups was quite small. The effect size, calculated using eta squared, was .05 which is considered rather small (Cohen, 1988). Post-hoc comparisons using the Tukey HSD test indicated that the mean score for group 1 $(\mathrm{M}=2.83, \mathrm{SD}=.87)$ was significantly different from group $3(\mathrm{M}=3.34, \mathrm{SD}=.88)$ and group 4 $(\mathrm{M}=3.45, \mathrm{SD}=.81)$. Group $2(\mathrm{M}=3.11, \mathrm{SD}=.96)$ did not differ significantly from groups 1,3 and 4.

Another one-way analysis of variance between groups was conducted to explore the impact of years of service in education on accessibility. Participants were divided into four groups according to their years of service in education (group 1: 1-10, group 2: 11-20, group 3: 21-30, group 4: >30). There was a statistically significant difference at the accessibility scores for the four groups: $F(3,280)=5.61, p=.001$. Despite reaching statistical significance, the actual difference in mean scores between the groups was medium. The effect size, calculated using eta squared, was .06 which is considered medium (Cohen, 1988). Post-hoc comparisons using the Tukey HSD test indicated that the mean score for group $1(\mathrm{M}=2.90, \mathrm{SD}=.96)$ was significantly different from that of group $3(\mathrm{M}=3.49, \mathrm{SD}=.77)$. Group $2(\mathrm{M}=3.22, \mathrm{SD}=.92)$ and group $4(\mathrm{M}=3.38, \mathrm{SD}=.84)$ did not differ significantly from groups 1 and 3 .

The importance of teacher education in ICT is highlighted by its high acceptance rate. According to teachers' views, training in ICT is important $(\mathrm{M}=4.02, \mathrm{SD}=.75)$.

\section{Discussion}

We present the results of this study in order to investigate the factors that influence the use of ICT in the educational process in relation to the technological infrastructure of schools, accessibility, attitudes of teachers and their pedagogical perceptions. The results of the first research question contradict what other authors contend about the importance of a school's digital infrastructure in using ICT in the classroom (Aoki, Kim \& Lee, 2013; Bingimlas, 2009; De Witte \& Rogge, 2014; Lee, 2002). Primary education in the Greek educational system is characterized by the lack of infrastructure or the use of obsolete technology. Based on this fact, inaccessibility is a dominant factor that affects the use of ICT negatively during the educational process. In particular, there is lack of accessibility to the computer lab. As a result, the use of educational software and the Internet in collaborative learning is not exploited. In most schools there is only one organized computer lab that is used exclusively for the Computer Science course. The results confirm the importance attributed to the literature for mismatch over software availability compared to hardware (Bingimlas, 2009; Lee, 2002).

Concerning the second research question, the results show a positive relationship between the use of ICT in the classroom and the characteristics of teachers and their attitudes towards computers. The increased need for ICT training, positive attitudes towards computers and the use of ICT teaching practices confirm the relevance of the relationship. The high demand for training is considered to be the most important variable in relation to the use of ICT in the educational process. Surveys examining the results of Level B' training in ICT show its particular positive impact on teachers' attitudes towards computers and the increased use of new technologies. Equally important is the role of the perception of the teacher's self-esteem as it is highlighted in previous studies. Self-esteem is directly correlated with self-efficacy associated with technology integration in teaching (Lee \& Lee, 2014) or using digital learning materials (Kreijns et al., 2013). 
Regarding the third question, the results demonstrate teachers' pedagogical beliefs. Teachers in the Greek educational system are presented as radical constructivists and social constructivists. Practically, these two types of teachers equate radical constructivism and social constructivism. The teachers' beliefs have a positive relationship with the use of ICT in their classroom. The use of technology, and especially the Internet, during the educational process has slowly shifted the theoretical balance from behaviorism to constructivism. There is a shift from behavioral learning practices to learning design practices associated with the increased use of educational technologies; the shift stems also from the fact that many available technologies support structured learning platforms. But there are also several educators who support the combination of the two theories, because they can be used in conjunction with existing educational technology and the official educational software, most of which presupposes the principles of behaviorism. However, there are many factors that need to be taken into account when deciding which theory is most applicable in some practices, such as the curriculum, the need for assessment and the available resources (Weegar \& Pacis, 2012).

Teachers' views on accessibility in relation to their age and educational background are of particular interest. Younger teachers feel more excluded by their older colleagues as regards their accessibility to the digital infrastructure of the school. This can be explained by the greater involvement of young educators with ICT. As users of new technological applications, young educators have been trained in more modern educational systems and exposed to innovative teaching applications; consequently, they feel the need to apply their knowledge to the school environment in which they work. The same effect is also observed for teachers with fewer years of service. Their access to digital media is smaller than that of their colleagues with more years of service.

Variables associated with demographic characteristics such as gender, specialization and pedagogical training of teachers do not have a significant statistical relationship with the use of ICT.

\section{Conclusion}

This study has enabled us to confirm, or verify, the view that the amount of ICT infrastructure in Greek schools is very low. In fact, it is among the most limited in Europe. The lack of infrastructure in the Greek educational system runs counter to similar surveys that control relevant factors in educational systems in other countries in Europe. An example is the Spanish education system where infrastructure is one of the highest in Europe (Gil-Flores et al., 2017). According to Wastiau, Blamire, Kearney, Quittre, Van de Gaer and Monseur (2013), at EU level on average, between 25 and 35\% of students in grades 4 are in highly equipped schools. Conversely, less than $20 \%$ of students in grade 4 are in such schools in countries such as Bulgaria, Croatia, Greece, Hungary, Italy, Slovakia, Slovenia, Poland, Romania and Turkey. However, infrastructure alone is not enough. The use of ICT in classrooms is limited by the characteristics of teachers, in particular because of the high ICT training needs of teachers and the lack of development of interdisciplinary knowledge. Using this information, interventions should be made to encourage the use of ICT in Greek schools.

Continuous teacher training in ICT is a general requirement. However, according to the recommendations of various authors (Bingimlas, 2009; Drent \& Meelissen, 2008; Koh \& Chai, 2014; Lee \& Lee, 2014; Valtonen et al., 2015), knowledge should be incorporated into the development of the teaching procedures in the classroom. In order to achieve this goal, training proposals should focus on groups of teachers working in the same school (Vanderlinde et al., 2014). This design will result in encouraging professional co-operation, developing innovative teaching methods in conjunction with a constructive focus. 
In conclusion, successful implementation of educational technology in schools does not depend solely on the accessibility or the lack of any single factor. It depends on a dynamic process involving a set of interrelated factors, such as adequate support from managers, the existence of logistics infrastructure, the acceptance of the utility of the use of technology by the teacher, the continuous updating and acquisition of knowledge by the teacher in relation to ICT and their correlation with innovative teaching methods. Moreover, as it is quite frequent with research, one the weaknesses of our study need to be highlighted. Regarding the dependent variables, they were considered on the basis of the information that was provided by teachers. However, it would be interesting to contrast this information with information obtained from other sources, such as students. In addition, it would be interesting if future studies included teacher-related variables such as motivation theory, in particular their self-determination within their professional environment.

\section{Acknowledgements}

This research did not receive any specific grant from funding agencies in the public commercial, or not-for-profit sectors.

The authors declare no competing interests.

\section{References}

Al-Khaldi, M., \& Al-Jabri, M. (1998). The relationship of attitudes to computer utilization: new evidence from a developing nation. Computers in Human Behavior, 14, 23-42.

Aoki, H., Kim, J., \& Lee, W. (2013). Propagation \& level: Factors influencing in the ICT composite index at the school level. Computers \& Education, 6o(1), 310-324.

https://doi.org/10.1016/j.compedu.2012.07.013.

Anderson, R. (2008). Implications of the information and knowledge society for education. In: J. Voogt \& G. Knezek (Eds.), International handbook of information technology in primary and secondary education (5-22). New York: Springer.

Beckers, J., \& Schmidt, H. (2001). The structure of computer anxiety: a six-factor model. Computers in Human Behavior, 17, 35-49.

Beckers, J., \& Schmidt, H. (2003). Computer experience and computer anxiety. Computers in Human Behavior, 19, 785-797.

Berrett, B., Murphy, J., \& Sullivan, J. (2012). Administrator insights and reflections: Technology integration in schools. The Qualitative Report, 17(1), 200-221.

Bingimlas, K. A. (2009). Barriers to the successful integration of ICT in teaching and learning environments: A review of the literature. Eurasia Journal of Mathematics, Science \& Technology Education, 5(3), 235-245.

Buabeng-Andoh, C. (2012). Factors influencing teachers' adoption and integration of information and communication technology into teaching: A review of the literature. International Journal of Education and Development using Information and Communication Technology, 8(1), 136155 .

Commission of the European Communities (2005). i201O - A European Information Society for growth and employment. Retrieved from http://eurlex.europa.eu/LexUriServ/LexUriServ.do?uri=COM:2005:0229:FIN:EN:PDF. 
Cohen, J. W. (1988). Statistical power analysis for the behavioral sciences (2 ${ }^{\text {nd }}$ ed.). Hillsdale, NJ: Lawrence Erlbaum Associates.

Cohen, L., \& Manion, L. (1994). Research methods in education (4 ${ }^{\text {th }}$ ed.). London: Routledge.

Cosgrove, J., Butler, D., Leahy, M., Shiel, G., Kavanagh, L., \& Creaven, A-M. (2013). ICT in Schools Census 2013: Post-Primary Questionnaire. Retrieved from

http://www.pdsttechnologyineducation.ie/en/Technology/ICT-Census-2013-PostPrimary/ICTCensus2013-PP-Teacher-Eng.pdf.

Davis, F. (1989). Perceived usefulness, perceived ease of use, and user acceptance of information technology, MIS Quarterly, 13(3), 319-340.

Davis, F. (1993). User acceptance of information technology: system characteristics, user perceptions and behavioural impacts. Int. J. Man-Machine Studies, 38, 475-487.

Day, C. (1999). Developing teachers: The challenges of lifelong learning. Psychology Press.

De Witte, K., \& Rogge, N. (2014). Does ICT matter for effectiveness and efficiency in mathematics education? Computers \& Education, 75, 173-184. https://doi.org/10.1016/j.compedu.2014.02.012

Dede, C. (2008). Theoretical perspectives influencing the use of information technology in teaching and learning, International Handbook of Information Technology in Primary and Secondary Education (43-62). New York: Springer.

Deng, F., Chai, C. S., Tsai, C. C., \& Lee, M. H. (2014). The relationships among Chinese practicing teachers' epistemic beliefs, pedagogical beliefs and their beliefs about the use of ICT. Journal of Educational Technology \& Society, 17(2), 245-256.

Drent, M., \& Meelissen, M. (2008). Which factors obstruct or stimulate teacher educators to use ICT innovatively? Computers \& Education, 51(1), 187-199.

https://doi.org/10.1016/j.compedu.2007.05.001

Elliot, J. (1991). Action research for educational change. McGraw-Hill Education (UK).

European Commission (2009). Commission working document. Consultation on the future "EU2O2O" strategy. $\operatorname{COM(2009)} 647$ final. Retrieved from http://ec.europa.eu/dgs/secretariat_general/eu2020/docs/com_2009 647_en.pdf.

European Commission. (2013). Survey of schools: ICT in education. Retrieved from https://ec.europa.eu/digital-agenda/node/51275.

Flanagan, L., \& Jacobsen, M. (2003). Technology leadership for the twenty-first century principal. Journal of Educational Administration, 41(2), 124-142. https://doi.org/10.1108/09578230310464648

George, D., \& Mallery, P. (2003). SPSS for Windows step by step: A simple guide and reference. 11.0 update ( $4^{\text {th }}$ ed.). Boston: Allyn \& Bacon.

Gil-Flores, J., Rodríguez-Santero, J., \& Torres-Gordillo, J. J. (2017). Factors that explain the use of ICT in secondary-education classrooms: The role of teacher characteristics and school infrastructure. Computers in Human Behavior, 68, 441-449.

Good, T. L., \& Brophy J.E. (1990). Educational psychology: A realistic approach (4 ${ }^{\text {th }}$ ed). White Plains N.Y. Logman.

Hall, G. E., \& Hord, S. M. (2015). Implementing change: Patterns, principles and potholes (4 ${ }^{\text {th }}$ ed.). Upper Saddle River, NJ: Pearson.

Hargreaves, A., (1994). Changing teachers, changing times: Teachers' work and culture in the postmodern age. New York: Teachers College Press.

Ionita, I., \& Schiopu, D. (2010). Using principal component analysis in loan granting. Buletinul, 62(1), 8896. 
Kimmons, R., Miller, B. G., Amador, J., Desjardins, C. D., \& Hall, C. (2015). Technology integration coursework and finding meaning in pre-service teachers' reflective practice. Educational Technology Research and Development, 63(6), 809-829.

Knezek, G., Christensen, R., \& Fluke, R. (2003). Testing a will, skill, tool model of technology integration. Paper presented at the Annual Meeting of the American Educational Research Association. Chicago, IL, 21-25 April 2003.

Knezek, G., \& Christensen, R. (2003). Scientifically-based research on the impact of technology on reading achievement. Denton, TX: University of North Texas, Institute for the Integration of Technology into Teaching \& Learning.

Kumar, N., Rose, R.C., \& D’ Silva, J. L. (2008). Teachers' readiness to use technology in the classroom: An empirical study. European Journal of Scientific Research, 21(4), 603-616.

Lee, K. T. (2002). Effective teaching in the information era: Fostering an ICT-based integrated learning environment in schools. Asia-Pacific Journal for Teacher Education and Development, 5(1), 21-45.

Lee, Y., \& Lee, J. (2014). Enhancing pre-service teachers' self-efficacy beliefs for technology integration through lesson planning practice. Computers \& Education, 73, 121-128. https://doi.org/10.1016/j.compedu.2014.01.001

Legontis, A. (2015). Training of teachers in the Training Support Centers (CTT) and in the University Education Centers (Un.CT) in the use of ICT in the educational and teaching process. $\mathrm{PhD}$ Dissertation, University of Macedonia.

Lim, C. P. (2006). Effective integration of ICT in Singapore schools: Pedagogical and policy implications. Educational Technology Research and Development, 55(1), 83-116. https://doi.org/10.1007/s11423-006-9025-2

Lockwood, B., \& Cornell, R. (2013). School ICT infrastructure requirements for teaching computing. $A$ Computing at School (CAS) Whitepaper.

Koh, J. H. L., \& Chai, C. S. (2014). Teacher clusters and their perceptions of technological pedagogical content knowledge (TPACK) development through ICT lesson design. Computers \& Education, 70, 222-232. https://doi.org/10.1016/j.compedu.2013.08.017

Kreijns, K., Van Acker, F., Vermeulen, M., \& Van Buuren, H. (2013). What stimulates teachers to integrate ICT in their pedagogical practices? The use of digital learning materials in education. Computers in Human Behavior, 29(1), 217-225.

Mavroyorgos, G. (1999). The educational unit as an institution of formation and exercise of educational policy. In: Athanasoula-Reppas, A., Koutouzis, M., Mavroyorgos, G., Nitsopoulos, V. \& Halkiotis, D. (Eds.) Educational Management and Policy, Volume I.

Ministry of Education, Research and Religious Affairs (2016). Establishment of a separate department of new technologies and innovation at the Ministry of Education, Research and Religious Affairs. Law 4415/2016 GG159/A/6-9-2016.

Mishra, P., \& Koehler, M. J. (2006). Technological pedagogical content knowledge: A framework for teacher knowledge. Teachers College Record, 108, 1017-1054.

Ortiz, J., (2013). The economic crisis and its effect on education in Greece. PoliticOle. Retrieved from https://oleville.com/politicole/2013/09/24/567/.

Palaigeorgiou, G., (2006). Studying the structure and evolution of student-computer interaction. PhD Dissertation, Thessaloniki: A.U.Th.

Pickles, M. (2015) Greek tragedy of education opportunities. BBC News. Retrieved from http://www.bbc.com/news/business-34384671.

Plomaritis D., Maletskos A., \& Fousteris, N. (2015). Teachers' perceptions and suggestions on innovation and new technologies in education. In: G. Alexandratos, A. Tivas \& T. Arvanitis-Papadopoulou 
(Eds.), Proceedings of the $2^{\text {nd }}$ Scientific Conference of the Panhellenic Association of School Counselors: Educational Policies for the $21^{\text {st }}$ Century School.

Prawat, R. (1996). Learning community, commitment and school report. Curriculum Studies, 28(1).

Pelgrum, W. J., \& Voogt, J. (2009). School and teacher factors associated with frequency of ICT use by mathematics teachers: Country comparisons. Education and Information Technologies, 14(4), 293-308.

Romeo, G., Lloyd, M., \& Downes, T. (2012). Teaching teachers for the future (TTF): Building the ICT in education capacity of the next generation of teachers in Australia. Australasian Journal of Educational Technology, 28 (Special issue, 6), 949-964.

Sass, E. J. (2003) Your emerging theory / Philosophy of teaching and learning. Retrieved from http://www.employees.csbsju.edu/esass/learningratingscale.htm.

Smith, B., Caputi, P., \& Rawstorne, P. (2000). Differentiating computer experience and attitudes toward computers: an empirical investigation. Computers in Human Behavior, 16, 59-81.

Sekaran, U., \& Bougie, R. (2010). Research methods for business: A skill-building approach (5 ${ }^{\text {th }}$ ed.). West Sussex, UK: John Wiley \& Sons Ltd.

Stiegelbauer, S. (1992). Why we want to be teachers. Paper presented at the Annual Meeting of the American Educational Research Association, San Francisco.

Spector, J. M. (2010). An overview of progress and problems in educational technology. Interactive Educational Multimedia, 1, 27-37.

Tabachnick, B. G., \& Fidell, L. S. (2007). Using multivariate statistics ( $5^{\text {th }}$ ed.). Boston, MA: Allyn \& Bacon.

Thomas, L. G., \& Knezek, D. (2008). Information, communications, and educational technology standards for students, teachers, and school leaders. In: J. Voogt \& G. Knezek (Eds.), International handbook of information technology in primary and secondary education. New York: Springer.

Teo, T., Ursavas, O.F., \& Bahcekapili, E. (2012). An assessment of pre-service teachers' technology acceptance in Turkey: A structural equation modeling approach. The Asia-Pacific Education Researcher, 21(1), 199-210.

Tezci, E. (2011). Turkish primary school teachers' perceptions of school culture regarding ICT integration. Educational Technology Research and Development, 59(3), 429-443. https://doi.org/10.1007/s11423-011-9205-6

Tondeur, J., van Braak, J., \& Valcke, M. (2007). Towards a typology of computer use in Primary Education. Journal of Computer Assisted Learning, 23(3), 197-206.

Tondeur, J., van Keer, H., van Braak, J., \& Valcke, M. (2008). ICT integration in the classroom: Challenging the potential of a school policy. Computers \& Education, 51(1), 212-223. https://doi.org/10.1016/j.compedu.2007.05.003

Tondeur, J., van Braak, J., Ertmer, P. A. \& Ottenbreit-Leftwich, A. (2016). Understanding the relationship between teachers' pedagogical beliefs and technology use in education: a systematic review of qualitative evidence. Educational Technology Research and Development, 1-21.

Valtonen, T., Kukkonen, J., Kontkanen, S., Sormunen, K., Dillon, P., \& Sointu, E. (2015). The impact of authentic learning experiences with ICT on pre-service teachers' intentions to use ICT for teaching and learning. Computers \& Education, 81, 49-58. https://doi.org/10.1016/j.compedu.2014.09.008

Vanderlinde, R., \& Van Braak, J. (2010). The e-capacity of primary schools: Development of a conceptual model and scale construction from a school improvement perspective. Computers \& Education, 55(2), 541-553. https://doi.org/10.1016/j.compedu.2010.02.016 
Vanderlinde, R., van Braak, J., \& Dexter, S. (2012). ICT policy planning in a context of curriculum reform: Disentanglement of ICT policy domains and artifacts. Computers \& Education, 58(4), 13391350. https://doi.org/10.1016/j.compedu.2011.12.007

Vanderlinde, V., Aesaert, K., \& van Braak, J. (2014). Institutionalised ICT use in primary education: A multilevel analysis. Computers \& Education, 72, 1-10.

https://doi.org/10.1016/j.compedu.2013.10.007

Yuen, A. H. K., Law, N., \& Wong, K. C. (2003). ICT implementation and school leadership: Case studies of ICT integration in teaching and learning. Journal of Educational Administration, 41(2), 158170.https://doi.org/10.1108/09578230310464666

Wastiau, P., Blamire, R., Kearney, C., Quittre, V., Van de Gaer, E., \& Monseur, C. (2013). The use of ICT in education: A survey of schools in Europe. European Journal of Education, 48(1), 11-27. https://doi.org/ 10.1111/ejed.12020

Weegar, M. A., \& Pacis, D. (2012). A Comparison of two theories of learning behaviorism and constructivism as applied to face-to-face and online learning. Retrieved from https://www.gcasa.com/conferences/manila/papers/Weegar.pdf.

Wu, D., Yu, X., Rao, J., \& Yu, L. (2016). Comparative study on the status and strategies of infrastructure construction of ICT in education between China and the United States. ICT in Education in Global Context, 95-106. https://doi.org/10.1007/978-3-662-47956-8 5 